\title{
ЗМІНИ У ЦИФРОВИХ КОМУНІКАЦІЯХ В УКРАЇНІ У ПЕРІОД ПОЯВИ СОЦІАЛЬНИХ МЕРЕЖ
}

\section{CHANGES IN DIGITAL COMMUNICATIONS IN UKRAINE DURING THE EMERGENCE OF SOCIAL NETWORKS}

\author{
Мельник Анатолій Віталійович \\ старший викладач, \\ Національний університет «Києво-Могилянська академія» \\ ORCID: https://orcid.org/0000-0002-8012-1587 \\ Melnyk Anatolii \\ National University of "Kyiv-Mohyla Academy"
}

\begin{abstract}
Стаття присвячена актуальним питанням розвитку цифрових комунікацій в Україні в умовах появи соціальних мереж. Проаналізовано та систематизовано основні фрактори, що ставали рушієм у змін у цифровому середовищі та причиною стрімкого росту соціальних медіа. Досліджено регіональну специсіку діджитал комунікацій у порівнянні з загальносвітовим контекстом. Акцентовано на змінах у підходах до діджитал комунікацій, рушієм яких стали соціальні мережі. Висновки демонструють необхідність критичного підходу до цифрових платформ, особливо для бізнесу та організацій, під час довгострокового планування комунікацій в Інтернеті.

Ключові слова: діджитал комунікації, соціальні мережі, цифрове середовище, Інтернет-платсорми.
\end{abstract}

Статья посвящена актуальным вопросам развития цифрровых коммуникаций в Украине в условиях появления социальных сетей. Проанализированы и систематизированы основные фракторы, которые становились причинами изменений в цифровой среде и стремительного роста социальных медиа. Исследовано региональную специсику диджитал коммуникаций в сравнении с общемировым контекстом. Акцентировано на изменениях в подходах к диджитал коммуникациям, двигателем которых стали социальные сети. Выводы демонстрируют необходимость критического подхода к цифрровым платформам, особенно для бизнеса и организаций, во время долгосрочного планирования коммуникаций в Интернете.

Ключевые слова: диджитал коммуникации, социальные сети, цифровая среда, Интернет-платорормы.

This article is devoted to the topical issue of digital communications development in Ukraine in the conditions of the emergence of social networks. The main factors that became the driving force in the changes in the digital environment and the reasons for the rapid growth of social media are analyzed and systematized. Specific regional aspects in communications are investigated in comparison with the global context. We drew attention to the problems of copyright in Ukraine, especially in social networks. In Ukraine, there are many websites with illegal content. Among the key web platforms for the spread of pirated music and videos are Russian social networks. The growing popularity of social media was accompanied by an increase in the total number of Internet users in Ukraine. Emphasis is placed on changes in approaches to digital communication, driven by social networks. The emergence of social networks also coincided with the implementation of new technical standards, especially in web technologies, which opened up new technical possibilities. Social networks have been actively implementing the latest technological advances. Over time, the rapid development of social media has led to these tools getting into the hands of corporations. In the case of Ukraine, control over key digital communication channels gained by Russian corporations will lead to serious risks for national security during the war conflict that began in 2014. Social media is leading the movement against anonymity on the Internet. With the advent of the popularity of social networks, users publicly disclosing personal data is becoming the social norm. Practice shows that the "life cycle" of digital platforms relevant to Ukraine can be quite short. Platforms are coming, gaining popularity, declining, and then new ones gain in popularity. Some communication channels may be supplanted by others. Factors of change can be competition in the market, the emergence of new technologies and ideas, changes in the political situation, etc. The example in recent years shows that political decisions, such as sanctions and blockades, can significantly change the balance of power in the market of digital communications in a very short period. The findings illustrate the need for a critical approach to digital platforms in the long-term planning of digital communications for business and organizations.

Keywords: digital communications, social networks, internet platforms, online. 
Постановка проблеми. Цисррові комунікації на теренах України розвивалися з власною регіональною специфрікою, в атмосфрері відсутності контролю, нехтування авторським правом, впливу російських платфрорм та багатьох інших фракторів.

Експансія соціальних платформ призвела до наслідків для інших цифррових каналів комунікації, особливо тих, які не витримали конкуренції та фрактично перестали грати помітну роль у медіапросторі. Викликає занепокоєння монополія великих міжнародних корпорацій та фрактичний контроль над ключовими каналами комунікації в цифровому середовищі. Відповідь на питання, чому так сталося, ми пропонуємо шукати у аналізі періоду появи соціальних медіа.

Аналіз останніх досліджень і публікацій. Помітні звіти організацій та компаній, у фоккусі яких дослідження інтернет-аудиторії в Україні, з яких можна виділити: KMIC, TNS, Factum Group, BPK, IнAУ, GfK та інші. Середукраїнських дослідників з історіографрічної точки зору появу та розвиток соціальних мереж розглядає Пінчук О.П. [25]. Серьогін В.О. ще у 2011 році ставить питання про загрозу приватності користувачів з ростом популярності соціальних мереж [26]. Етап становлення соціальних медіа у полі зору Данько Ю.А., де акцентується на ризиках залежності від користування соціальними мережами [13]. Серед досліджень можливостей використання цифрових каналів комунікації для бізнесу можна згадати праці Коника Д.Л. [19], Курбана О.В. [21].

На Заході виділяються O'reilly Т. з його концепцією Web 2.0 [7]. Fuchs C з досить критичним поглядом на соціальні мережі та аналізом, як вони змінили комунікації [7]. Kaplan A.M. та Haenlein M. $з$ оглядом потенціалу та можливостей соціальних медіа [5]. Kietzmann J.H. 3 закликом до бізнесу серйозно ставитися до соціальних мереж [6] та інші.

Формулювання цілей статті (постановка завдання). Дослідити основні напрямки розвитку цисррових комунікацій в України в період появи соціальних мереж. Розкрити основні тенденції digital-комунікацій. Виокремити регіональні особливості у порівнянні з загальносвітовим контекстом.

Хронологічні рамки дослідження обумовлені появою соціальних мереж в українському сегменті Інтернету. Верхня межа: закріплення соціальних мереж у рейтингах топ-3 вебсайтів України за відвідуваністю у 2010-2012 рр.

Виклад основного матеріалу дослідження. Розвиток цифррових комунікацій нерозривно пов'язаний 3 впровадженням новітніх Інтернет-технологій. В українському сегменті Інтернету відзначаються важливі зміни. Збільшується загальна кількість інтернет-користувачів. За даними КМІС у період 3 2006 по 2012 рр. загальна кількість дорослого населення України, що користується інтернетом, зросла з 19\% до 43\% [27]. Поступово в Україні з'являється широкосмуговий доступ до Інтернет-мережі [15]. Національний інститут стратегічних досліджень, посилаючись на дані Національної комісії, що здійснює державне регулювання у ссрері зв язку та інформатизації, відзначає, що вже у період 3 2010 по 2012 рр. проникнення широкосмугового доступу до Інтернету в українських домогосподарствах зросло з 18\% до 34\% [15, с. 58].

Стало можливим передавати та отримувати значні обсяги інфрормації. Через Інтернет починають передаватися великі обсяги даних, зокрема мультимедійний контент. Оскільки перед користувачами відкрилися небачені доти можливості обміном інформацією, з'являються й побічні наслідки отриманої враз «безлімітної» Інтернет-свободи. У цей час Україна переживає ріст Інтернетпіратства і з часом стає одним із лідерів поширення «піратського» контенту $[12$, с. 6-7]. Виникають різноманітні «торенти», «варезники», фрайлообмінні мережі тощо. Супроводжуються цей процес відсутністю практично будь-якої регуляції цифррового середовища 3 боку держави. Показовим $€$ те, що навіть на комп'ютерах в системі МВС стоять «піратські» копії «Windows» [16].

Форуми. Раніше комунікація у вебсередовищі радше була односторонньою. Тоді як срорум дозволяв вже самим користувачам бути ініціаторами дискусії. На фрорумах вирішувались різноманітні питання. 3'являються форуми за інтересами: фооруми рибалок, програмістів, студентів, фооруми окремих міст чи районів, фроруми для працівників міліції, авіамоделістів та багато інших. Постає двостороння комунікація. Все більше платорорм орієнтовані на користувацький контент [7]. Користувачі починають самі наповнювати вебресурси. Форуми стають настільки популярними, що дуже багато сайтів мають при собі майданчики для обговорення, інколи навіть там, де без них можна обійтись. Вже згадані торенти часто були за своєю сутністю теж форумами, де самі ж користувачі ділились «піратським» контентом.

3 розвитком цифрового середовища постає проблема верифрікації інфрормації, яка 
там поширюється. Користувачі у «досоцмережному» періоді не надто прагнули публічно розкривати свої персональні дані. Відтак це відкривало значне поле для маніпуляцій. Окрім того, важко було зрозуміти, наскільки можна довіряти тому чи іншому користувачеві, прихованому за вигаданим псевдонімом, наскільки глибока його експертиза чи це та сама людина і т.і.

Поступово у популярних програмних рішеннях впроваджується фрункціонал для оцінки репутації користувачів. Як заслужити репутацію в Інтернеті? Активно публікувати контент, бути активним учасником обговорень. Один 3 показників за якими користувачі можуть оцінити репутацію іншого - це загальна кількість повідомлень. Пізніше - певні ранги, нагороди, які користувач отримує за активну участь в обговоренні. Згодом стає можливим ставити «плюс», вподобати, підтримати сказане користувачем. Так виникає передвісник «лайку» чи «вподобайки». У «Facebook» кнопка «Like» з'явиться тільки у 2010 році [2].

Окрім форумів, у «досоцмережний» період досить популярні онлайн-щоденники, Інтернет-блоги. Починався блог - великою розгорнутою публікацією на певну тему, а під ним обговорення учасниками спільноти. Серед помітних блогерських платорорм в Україні - «Живий журнал» [10], централізований сервіс створення блогів в межах однієї платформи. Блогери отримують серйозну на той час аудиторію [29]. На них починає звертати увагу бізнес. Однак, надалі зі ствердженням соціальних платорорм, сервіси текстових блогів поступово втратять свою популярність. На зміну їм, окрім соціальних мереж, приходить пізніше, зокрема, «YouTube».

Основними месенджерами були «ICQ» та «Skype». «ICQ» орієнтований на обмін текстовими повідомленнями. «Skype» робить ставку на розвиток голосового зв'язку. У застосунках користувачі месенджерів бачать перед собою списки друзів, їхні статуси та мають змогу обмінятися 3 ними миттєвими повідомленнями. На противагу операторам телефронного зв'язку, комунікація відбувається безкоштовно, що приваблює користувачів. 3 появою можливості завантажень додатків на мобільні пристрої, застосунки «ICQ» з'являються для мобільних телефонів. На додачу мобільні оператори пропонують доступні тарифи мобільного інтернету для населення, зокрема «безлімітні» [17].

Слід зазначити, що до 2010 року «ICQ» достатньо потужний та фрункціональний застосунок. Окремі сучасні месенджери й донині мають бідніший функціонал у порівнянні 3 «ICQ» того періоду. Але у 2010 році «ICQ» купує «Digital Sky Technologies» [9]. У подальші роки «ICQ» зникає з поля зору. Вірогідно, занепад «ICQ» слід вбачати у неспроможності нових власників відповісти на ті виклики, які поставили перед ними нові соціальні платфрорми [11].

Ріст популярності соціальних платформ. Стрімко збільшується кількість Інтернет-користувачів. З'являються соціальні мережі. Найпопулярніші соціальні мережі для України на початку - це «ВКонтакті» та «Однокласники», серед молоді та старшої групи населення відповідно. Спершу соціальні мережі - статичні вебсайти з достатньо обмеженим фрункціоналом. Користувачам вони цікаві передусім для підтримки соціальних зв'язків зі своїми друзями, знайомими, однокласниками тощо.

До 2014 активно впроваджується новий стандарт HTML5 [8]. Внаслідок цього у вебтехнологіях відбуваються революційні зміни [1]. Новий стандарт покращив роботу з мультимедіа та запропонував нові можливості для розробників.

Як тільки браузери рапортують про підтримку тих чи інших рішень, соціальні мережі миттєво впроваджують нові розробки [4]. Імплементація нових технічних можливостей поставила під удар інші канали комунікації, які не встигали за розвитком технологій.

Довгий час в Україні «Facebook» не мав серйозних позицій. Основний конкурент, сайт «ВКонтакті» майже повністю копіював його фуункціонал і інтерсейс [18]. У деяких аспектах за словами Павла Дурова був навіть більш фрункціональний [22]. Окремі користувачі приходили у «ВКонтакті» заради музики і відео [14]. У певний момент він став ледь не одним 3 найбільших безкоштовних каталогів мультимедіа, у тому числі піратського контенту [18]. Звісно, «Фейсбуку», з його політикою щодо авторських прав, було важко конкурувати. По-справжньому лідерські позиції «Facebook» отримає лише після блокування російських сайтів у 2017 році [24].

Кінець анонімних комунікацій. До соціальних мереж комунікації в українському Інтернеті були здебільшого анонімні. Навіть 3 розвитком соціальних мереж користувачі неохоче розкривали публічно справжні свої імена, ховаючись за псевдонімами. Соціальні мережі поступово взяли курс на деанонімізацію користувачів. Використання несправж- 
нього імені стає суперечити правилам та ставати приводом для блокування аккаунту. Для розблокування ж соціальні мережі починають просити у користувачів підтвердження особистості - скани документів тощо.

Окрім того соціальні мережі змушують розкривати друзів користувачів [23] та інші дані. Незважаючи на протести, соцмережі перемогли. Соціальні медіа перестали бути анонімними, а за ними й інші цифрові канали комунікації. Розкривати свої персональні дані публічно стало нормою.

Сорормувалась централізована модель, де комунікація користувачів відбувається повністю на ресурсах переважно комерційних компаній. Компанія-власник такого Інтернетресурсу має повний контроль над активністю користувачів, водночас бере на себе відповідальність за безперебійну роботу всіх сервісів, оновлення, дотримання законодавства тощо.

Як видно з огляду ключових Інтернет-платфрорм, панівною виявилась централізована модель. Спроби самоорганізації користувачів переважно досі поступалася наявним ресурсами великих комерційних гравців [31]. Утім, за позицією Tim Berners-Lee, винахідника «World Wide Web», викликає занепокоєння, що ключові цифррові канали комунікацій опинились в руках у великих корпорацій. Можливий і інший шлях - децентралізації [32].

У випадку України ключові соціальні мережі у 2006-2012 рр. опинилися під контролем російських компаній. У подальшому мережею ширитимуться повідомлення про зв'язок їх із спецслужбами [18]. Пізніше з загостренням ситуації в Донецькій, Луганській областях та Криму, це стане національною загрозою для України. У 2017 році Україна заблокує ключові російські веб-сайти.

Висновки. Отже, цифррові комунікації в Україні в умовах появи та росту популярності соціальних медіа розвивались з деякими регіональними особливостями відносно загальносвітового контексту. Відсутність регуляції, контролю та позиції власників ключових платформ щодо авторського права стимулювала розвиток Інтернет-піратства. Часом наявність «піратського» контенту ставала обґрунтуванням для користувачів використання тих чи інших платорорм, на кшталт: «Я «ВКонтакті» заради музики».

Стрімкий ріст популярності соціальних медіа збігся в часі 3 ростом проникнення Інтернету в Україні. Очевидно, для деяких користувачів необхідність бути присутнім у першу чергу у соціальних мережах могла бути одним з ключових аргументів при рішенні приєднати своє домогосподарство до Інтернету. Таким чином можна припустити, що соціальні мережі могли бути одним з рушіїв загального збільшення Інтернет-користувачів.

3 впровадженням нових технічних стандартів, соціальні мережі швидко модернізуються та обростають новим фрункціоналом. Стрімкий технологічний ривок слід розцінювати як один з фундаментів вибухового росту популярності.

Соціальні мережі змінили підхід до комунікації в циорровому середовищі. Показовим прикладом $€$ унормування публічного розкриття користувачами своїх персональних даних, на противагу анонімності у «досоцмережний» період.

Аналіз розвитку тих чи інших платсорм показує, що «життєвий цикл» digital-платорорм часто може бути досить короткий. Існує ряд ризиків, таких як: блокування, продаж новому керівництво, зникнення тих чи інших фрункцій, введення плати за користування, зміна алгоритмів роботи та інше. Бізнесу слід враховувати цей фракт під час довгострокового планування своєї діяльності та використання тих чи інших digital-інструментів, зокрема соціальних медіа.

\section{СПИСОК ВИКОРИСТАНИХ ДЖЕРЕЛ:}

1. Anthes G. HTML5 leads a web revolution. Communications of the ACM. 2012. T. 55. № 7. C. 16-17.

2. Facebook To Release A "Like" Button For the Whole Darn Internet. URL: https://techcrunch.com/2010/03/25/ facebook-to-release-a-like-button-for-the-whole-darn-internet/ (дата звернення: 21.02.2021).

3. Fuchs C. Social media: A critical introduction. SAGE publications Limited, 2021.

4. Gutiérrez R. T. Understanding the role of digital commons in the web; The making of HTML5. Telematics and Informatics. 2018. T. 35. № 5. C. 1438-1449.

5. Kaplan A. M., Haenlein M. Users of the world, unite! The challenges and opportunities of Social Media. Business horizons. 2010. T. 53. № 1. C. 59-68.

6. Kietzmann J. H. Social media? Get serious! Understanding the functional building blocks of social media. Business horizons. 2011. T. 54. № 3. C. 241-251.

7. O'Reilly T. What is Web 2.0: Design patterns and business models for the next generation of software. Communications \& strategies. 2007. № 1. C. 17-33. 
8. Page R. Researching language and social media: A student guide. NY : Routledge, 2014. $201 \mathrm{c}$.

9. What ever happened to ICQ? URL: https://www.techspot.com/article/1771-ісq/ (дата звернення: 14.02.2021).

10.Белей Л. Інтернет-блоґ "Живий Журнал" як мовна спільнота: статус та специфріка комунікації. Сучасні проблеми мовознавства та літературознавства. 2008. № 12. С. 67-69.

11. Бондарєв О. Стукни в аську. Чому легендарний месенджер ICQ відправився на звалище історії. URL: https://nv.ua/ukr/techno/gadgets/stukni-v-asku-chomu-legendarnij-mesendzher-icq-vidpravivsja-na-zvalishcheistoriji-275229.html (дата звернення: 14.02.2021).

12. Вавдіюк Н. С., Іванчук В. Ю. Оцінка економічного піратства в Україні: методи протидії. Економічний форум. 2016. № 4. С. 4-15.

13. Данько Ю. А. Соціальні мережі як форма сучасної комунікації: плюси і мінуси. Сучасне суспільство. 2012. № 2. C. 179-184.

14.Довженко О. Чому Facebook, а не «Вконтакте» URL: https://ms.detector.media/onlain-media/post/ 9950/2011-04-06-chomu-facebook-a-ne-vkontakte/ (дата звернення: 14.02.2021).

15.Дубов Д. В., Ожеван М. А. Широкосмуговий доступ до мережі інтернет як важлива передумова інноваційного розвитку України : аналіт. доп. Київ : НІСД, 2013. 108 с.

16. Закусило Т. Пірати з МВС. Україна молода. 2012. URL: https://umoloda.kyiv.ua/number/2024/116/72098/ (дата звернення: 20.02.2021).

17. Интернет 2.5G Безлимит. URL: https://www.lifecell.ua/ru/mobilnyi-internet/tarify/2G_unlim/ (дата звернення: 14.02.2021).

18. Как «ВКонтакте» стала главной соцсетью России - и почему перестала ей быть. URL: https://secretmag.ru/ stories/vkontakte-14.htm (дата звернення: 14.03.2021).

19. Конык Д., Рендер С. Расставьте сети. Как использовать Интернет в интересах вашого бизнеса. Київ : ЛИК, 2011. 120 с.

20. Крайнікова Т. Профріль українського інтернет-користувача (аналіз вторинних соціологічних досліджень). Вісник Книжкової палати. 2014. № 2. С. 48-51.

21. Курбан О. В. PR у маркетингових комунікаціях : навч. посіб. Київ : Кондор-Видавництво, 2014. 246 с.

22. Павел Дуров: «Facebook в последние годы теряет пользователей в CHГ». URL: https://vc.ru/social/2513pavel-durov-facebook-lost-users-sng (дата звернення: 10.03.2021).

23. Паника по поводу приватности ВКонтакте - разъяснения. URL: https://habr.com/ru/post/113786/ (дата звернення: 20.02.2021).

24. После блокировки "ВКонтакте" аудитория Facebook за сутки выросла на 35\%. URL: https://uww.epravda.com.ual rus/news/2017/05/19/625061/ (дата звернення: 20.02.2021).

25. Пінчук О. П. Історико-аналітичний огляд розвитку соціальних мережних технологій і перспектив їх використання у навчанні. Інформаційні технології і засоби навчання. 2015. Т. 48. Вип. 4. С. 14-34.

26. Серьогін В. О. Соціальні мережі як загроза прайвесі. Форум права. 2011. № 2. С. 822-827.

27. Харченко Н. Динаміка користування Інтернет в Україні: травень 2017. Київський міжнародний інстиmym соціології. 2017. URL: http://www.kiis.com.ua/?lang=ukr\&cat=reports\&id=705 (дата звернення: 10.02.2021).

28. Хилько М. М., Корнєєв В. М. Вплив контенту засобів масової комунікації на український соціум. Current issues of mass communication. 2014. № 16. C. 57-68.

29. Хінкулава К. Дискусія на Бі-Бі-Сі: Блог як комунікації. 2008. URL: http://www.bbc.co.uk/ukrainian/indepth/ story/2008/01/080119_blog_interactive_is.shtml (дата звернення: 14.02.2021).

30. Черниш Р. Ф. Соціальні мережі як один із інструментів накопичення та протиправного використання персональних даних громадян. Проблеми законності. 2017. № 136. С. 205-214.

31. Halpin H. Decentralizing the social web. International Conference on Internet Science. Springer, Cham, 2018. C. 187-202.

32. Interview: Web inventor Tim Berners-Lee thinks his creation is out of control. Here's his plan to save it. URL: https://www.sciencefocus.com/future-technology/interview-web-inventor-tim-berners-lee-thinks-his-creationis-out-of-control-heres-his-plan-to-save-it/ (дата звернення: 21.04.2021).

\section{REFERENCES:}

1. Anthes, G. (2012). HTML5 leads a web revolution. Communications of the ACM, 55(7), 16-17.

2. Facebook To Release A "Like" Button For the Whole Darn Internet. Retrieved from: https://techcrunch.com/ 2010/03/25/facebook-to-release-a-like-button-for-the-whole-darn-internet/

3. Fuchs, C. (2021). Social media: A critical introduction. SAGE publications Limited. 
4. Gutiérrez, R. T. (2018). Understanding the role of digital commons in the web; The making of HTML5. Telematics and Informatics, 35(5), 1438-1449. https://doi.org/10.1016/j.tele.2018.03.013

5. Kaplan, A. M., \& Haenlein, M. (2010). Users of the world, unite! The challenges and opportunities of Social Media. Business horizons, 53(1), 59-68. https://doi.org/10.1016/j.bushor.2009.09.003

6. Kietzmann, J. H., Hermkens, K., McCarthy, I. P., \& Silvestre, B. S. (2011). Social media? Get serious! Understanding the functional building blocks of social media. Business horizons, 54(3), 241-251. https://doi.org/10.1016/ j.bushor.2011.01.005

7. O'reilly, T. (2007). What is Web 2.0: Design patterns and business models for the next generation of software. Communications \& strategies, (1), 17-33. Retrieved from: https://papers.ssrn.com/sol3/papers.cfm?abstract_ $\mathrm{id}=1008839$

8. Page, R., Unger, J. W., Zappavigna, M., \& Barton, D. (2014). Researching language and social media: A student guide. Routledge.

9. What ever happened to ICQ? Retrieved from: https://www.techspot.com/article/1771-icq/

10. Belei, L. (2008). Internet-blog "Zhyvyi zhurnal" yak movna spilnota: status ta spetsyfika komunikatsii [Online blog "Livejournal" as a language community: status and specifics of communication]. Suchasni problemy movoznavstva ta literaturoznavstva - Modern problems of linguistics and literature, 12, 67-69. Retrieved from: https://dspace.uzhnu.edu.ua/jspui/bitstream/lib/24049/1/Лeсь\%20БЕЛЕЙ.pdf (in Ukrainian)

11. Bondariev, O. (2016). Stukny v asku. Chomu lehendarnyi mesendzher ICQ vidpravyvsia na zvalyshche istorii [Knock in ICQ. Why the legendary ICQ messenger came to the trash of history]. Retrieved from: https://nv.ua/ukr/ techno/gadgets/stukni-v-asku-chomu-legendarnij-mesendzher-icq-vidpravivsja-na-zvalishche-istoriji-275229.html (in Ukrainian)

12. Vavdiiuk, N. S., \& Ivanchuk, V. Yu. (2016). Otsinka ekonomichnoho piratstva v Ukraini: metody protydii [Assessment of economic piracy in Ukraine: methods of counteraction]. Ekonomichnyi forum - Economic forum, (4), 4-15. Retrieved from: http://www.irbis-nbuv.gov.ua/cgi-bin/irbis_nbuv/cgiirbis_64.exe?C21COM=2\&/21DBN=UJRN\&P21DBN=UJRN\&IMAGE_FILE_DOWNLOAD=1\&Image_file_name=PDF/ecfor_2016_4_3.pdf (in Ukrainian)

13. Dan'ko, Yu. A. (2012). Sotsial'ni merezhi yak forma suchasnoyi komunikatsiyi: plyusy i minusy [Social networks as a form of modern communication: pros and cons]. Suchasne suspil'stvo - Modern Society, (2), 179-184. Retrieved from: http://www.irbis-nbuv.gov.ua/cgi-bin/irbis_nbuv/cgiirbis_64.exe?C21COM=2\&l21DBN=UJRN\&P21DBN=UJRN\&IMAGE_FILE_DOWNLOAD=1\&Image_file_name=PDF/cuc_2012_2_25.pdf (in Ukrainian)

14.Dovzhenko, O. (2011). Why Facebook and not "Vkontakte". Retrieved from: https://ms.detector.media/ onlain-media/post/9950/2011-04-06-chomu-facebook-a-ne-vkontakte/ (in Ukrainian)

15. Dubov, D. V. (2014). Shyrokosmuhovyy dostup do merezhi Internet yak vazhlyva peredumova innovatsiynoho rozvytku Ukrayiny [Broadband access to the Internet as an important prerequisite for innovative development of Ukraine]. Stratehichni priorytety - Strategic Priorities, (1), 206-207. Retrieved from: https://niss.gov.ua/sites/default/ files/2013-06/0611_dop.pdf (in Ukrainian)

16.Zakusylo T. (2012). Piraty z MVS [Pirates from the Ministry of Internal Affairs]. Retrieved from: https://umoloda.kyiv.ua/number/2024/116/72098 (in Ukrainian)

17. Internet 2.5G Bezlimitnyi [Internet 2.5G Unlimited] (n.d.). Retrieved from: https://www.lifecell.ua/ru/ mobilnyi-internet/tarify/2G_unlim/ (in Russian)

18. Kuzmin, I. (2020). Kak «VKontakte» stala glavnoy sotsset'yu Rossii - i pochemu perestala yey byt' [How VKontakte became the main social network in Russia - and why ceased to be the first]. Retrieved from: https://secretmag.ru/stories/vkontakte-14.htm (in Russian)

19. Konyk, D., \& Render, S. (2011). Rasstav'te seti. Kak ispol'zovat' Internet $v$ interesakh vashego biznesa [Spread the nets. How to Use the Internet to Benefit Your Business]. Kyiv: OOO Kompaniya LIK. (in Russian)

20. Kraynikova, T. (2014). Profil' ukrayins'koho internet-korystuvacha (analiz vtorynnykh sotsiolohichnykh doslidzhen') [Profile of the Ukrainian Internet user (analysis of secondary sociological research)]. Visnyk knyzhkovoyi palaty - Bulletin of the Book Chamber, (2), 48-48. Retrieved from: http://www.irbis-nbuv.gov.ua/cgi-bin/ irbis_nbuv/cgiirbis_64.exe?C21COM=2\&I21DBN=UJRN\&P21DBN=UJRN\&IMAGE_FILE_DOWNLOAD=1\&Image_file_name=PDF/vkp_2014_2_16.pdf (in Ukrainian)

21. Kurban, O. V. (2014). $P R$ u marketynhovykh komunikatsiyakh [PR in marketing communications]. Kyiv: Kondor-Vydavnytstvo. (in Ukrainian)

22. Fedorov, P. (2013). Pavel Durov: «Facebook v posledniye gody teryayet pol'zovateley v SNG» [Pavel Durov: "Facebook has been losing users in the CIS in recent years"]. Retrieved from: https://vc.ru/social/2513-pavel-durovfacebook-lost-users-sng (in Russian)

23. Panika po povodu privatnosti VKontakte - razyasneniya [Panic over VKontakte privacy - clarifications]. (2011). Retrieved from: https://habr.com/ru/post/113786/ (in Russian) 
24. Posle blokirovki "VKontakte" auditoriya Facebook za sutki vyrosla na 35\% [After blocking VKontakte, the Facebook audience increased by 35\% during the day] (2017). Retrieved from: https://www.epravda.com.ua/rus/ news/2017/05/19/625061/ (in Russian)

25. Pinchuk, O. P. (2015). Istoryko-analitychnyy ohlyad rozvytku sotsial'nykh merezhnykh tekhnolohiy i perspektyv yikh vykorystannya u navchanni [Historical and analytical review of the development of social network technologies and prospects for their use in education]. Informatsiyni tekhnolohiyi i zasoby navchannya - Information technology and teaching aids, 48(4), 14-34. Retrieved from: http://nbuv.gov.ua/UJRN/ITZN_2015_48_4_4 (in Ukrainian)

26. Ser'ohin, V. O. (2011). Sotsial'ni merezhi yak zahroza prayvesi [Social networks as a threat to privacy]. Forum prava - Law Forum, (2), 822-827. Retrieved from: http://www.irbis-nbuv.gov.ua/cgi-bin/irbis_nbuv/cgiirbis_64. exe?C21COM=2\&I21DBN=UJRN\&P21DBN=UJRN\&IMAGE_FILE_DOWNLOAD=1\&Image_file_name=PDF/FP_ index.htm_2011_2_133.pdf (in Ukrainian)

27. Kharchenko, N. (2017). Dynamika korystuvannya Internet v Ukrayini: traven' 2017 [Dynamics of Internet usage in Ukraine: May 2017]. Retrieved from: http://www.kiis.com.ua/?lang=ukr\&cat=reports\&id=705 (in Ukrainian)

28. Khyl'ko, M. M., \& Kornyeyev, V. M. (2014). Vplyv kontentu zasobiv masovoyi komunikatsiyi na ukrayins'kyy sotsium [The impact of media content on Ukrainian society]. Current issues of mass communication, (16), 57-68. Retrieved from: http://www.irbis-nbuv.gov.ua/cgi-bin/irbis_nbuv/cgiirbis_64.exe?C21COM=2\&I21DBN=UJRN\&P21DBN= UJRN\&IMAGE_FILE_DOWNLOAD=1\&Image_file_name=PDF/apmk_2014_16_8.pdf (in Ukrainian)

29. Khinkulava, K. (2008). Dyskusiya na Bi-Bi-Si: Bloh yak komunikatsiyi [Discussion on the BBC: Blog as communication]. Retrieved from: http://www.bbc.co.uk/ukrainian/indepth/story/2008/01/080119_blog_interactive_ is.shtml (in Ukrainian)

30. Chernysh, R. (2017). Sotsial'ni merezhi yak odyn iz instrumentiv nakopychennya ta protypravnoho vykorystannya personal'nykh danykh hromadyan [Social networks as one of the tools for the accumulation and illegal use of personal data of citizens]. Problemy zakonnosti - Problems of legality, (136), 205-214. Retrieved from: http://www.irbis-nbuv.gov.ua/cgi-bin/irbis_nbuv/cgiirbis_64.exe?C21COM=2\&I21DBN=UJRN\&P21DBN=UJRN\&IMAGE_FILE_DOWNLOAD=1\&Image_file_name=PDF/Pz_2017_136_23.pdf (in Ukrainian)

31. Halpin, H. (2018). Decentralizing the social web. International Conference on Internet Science. Springer, Cham, 187-202.

32. Interview: Web inventor Tim Berners-Lee thinks his creation is out of control. Here's his plan to save it. Retrieved from: https://www.sciencefocus.com/future-technology/interview-web-inventor-tim-berners-lee-thinks-hiscreation-is-out-of-control-heres-his-plan-to-save-it/ 